\title{
Sexing murine embryos with an indirect immunofluorescence assay using phage antibody B9-Fab against SDM antigen
}

\author{
Naidong $\mathrm{WANG}^{1) \#}$, Anwen YUAN ${ }^{1) \#}$, Jun $\mathrm{MA}^{1)}$, Zhibang $\mathrm{DENG}^{1)}$ and Liqun $\mathrm{XUE}^{1) *}$ \\ ${ }^{1)}$ College of Veterinary Medicine, Hunan Agricultural University, Changsha, Hunan Province 410128, PR China
}

(Received 9 October 2014/Accepted 22 January 2015/Published online in J-STAGE 8 February 2015)

\begin{abstract}
The use of serologically detectable male (SDM; also called H-Y) antigens to identify male embryos may be limited by the source of anti-SDM antibody. In the present study, novel anti-SDM B9-Fab recombinant clones (obtained by chain shuffling of an A8 original clone) were used to detect SDM antigens on murine embryos. Murine morulae and blastocysts $(n=138)$ were flushed from the oviducts of Kunming mice and incubated with anti-SDM B9-Fab for $30 \mathrm{~min}$ at $37^{\circ} \mathrm{C}$. With an indirect immunofluorescence assay, the membrane and inner cell mass had bright green fluorescence (presumptive males). Overall, $43.5 \%(60 / 138)$ were classified as presumptive males and $56.5 \%$ (78/138) as presumptive females, with 85.0 and $88.5 \%$ of these, respectively, confirmed as correct predictions (based on PCR analysis of a male-specific [Sry] sequence). We concluded that the anti-SDM B9-Fab molecule had potential for non-invasive, technically simple immunological sexing of mammalian embryos.

KEY WORDS: embryo sexing, immunofluorescence, PCR, phage antibody, SDM antigen
\end{abstract}

doi: 10.1292/jvms.14-0650; J. Vet. Med. Sci. 77(6): 711-714, 2015

Although invasive methods, including PCR, cytogenetics and analysis of sex chromatin using Y-specific DNA probes (e.g. Sry gene), have been used for sex determination [4, 9], they require relatively advanced technical skills (e.g. breaching the zona pellucida to biopsy an embryo). Therefore, there is a clear need to develop a simpler method to identify male and female embryos without compromising accuracy.

Serologically detectable male (SDM) antigen (also called $\mathrm{H}-\mathrm{Y}$, the Y-linked histocompatibility antigen) is a cell-surface glycoprotein complex in males $[10,14]$ that is expressed on embryos with more than eight cells $[6,10]$. Detection of embryo SDM antigen by immunofluorescence and developmental arrest with SDM antibody have been used to determine embryonic sex in various mammals. However, poor affinity and male specificity of conventional antibodies limited their utility for embryo sexing $[11,14]$.

In previous studies [12, 13], a second SDM phage antibody library was constructed, and a high-affinity phage antibody clone B9 was isolated using affinity maturation by light- and heavy-chain shuffling of an original phage antibody clone A8 derived from B cells of mice immunized with male spleen cells. Using a cell-based ELISA, the B9 clone was positively selected by male splenocytes, whereas female splenocytes were negatively selected [13]. Furthermore, B9 had higher affinity than both the original A8 clone and conventional antibodies (SDM serum) [13]. The objective of the

*Correspondence to: Xue, L., College of Veterinary Medicine, Hunan Agricultural University, Furong District, Changsha, Hunan Province 410128, PR China. e-mail: xlq@hunau.net

\#These authors contributed equally to this work.

(C)2015 The Japanese Society of Veterinary Science

This is an open-access article distributed under the terms of the Creative Commons Attribution Non-Commercial No Derivatives (by-nc-nd) License $<$ http://creativecommons.org/licenses/by-nc-nd/3.0/>. present study was to evaluate the presence of SDM antigen on murine embryos and sex murine embryos by an indirect immunofluorescence assay induced by B9-Fab. This phage antibody library was expected to provide new markers to investigate molecular mechanisms of SDM as a male-specific antigen for potential use in sex sorting of embryos in assisted reproduction.

The B9-Fab was prepared as reported [13]. The recombinant $\mathrm{pb} 3-\kappa-\mathrm{Fd}$ (light-and heavy-chain genes ligated into plasmid pComb3 vector) and DNA samples of B9 clone were transformed to E. coli XL1-Blue strain. Thereafter, expression of B9-Fab was induced by addition of IPTG (final concentration, $1.0 \mathrm{mmol} / \mathrm{l}$ ), and $\mathrm{B} 9-\mathrm{Fab}$ soluble proteins were separated by centrifugation $\left(10,000 \times \mathrm{g}\right.$ for $15 \mathrm{~min}$ at $\left.4^{\circ} \mathrm{C}\right)$. The quality of soluble Fab proteins in supernatant was assessed by non-reducing SDS-PAGE, followed by Coomassie Brilliant Blue staining, and was confirmed using horseradish peroxidase (HRP)-conjugated goat anti-mouse Fab (1:4,000, Pierce, Rockford, IL, U.S.A.) by western blot analysis, as described [13]. The end product B9 clone was selected for further analysis.

Morulae and blastocyst-stage embryos were recovered from superovulated Kunming female mice aged 8-10 weeks (SLAC Laboratory Animal Co., Ltd., Changsha, China), as described [2]. Maintenance of mouse colonies and all experimental procedures were approved by the Animal Welfare and Ethics Committee of Hunan Agricultural University. Thereafter, 5 to 8 murine embryos were placed in droplets $(30 \mu l)$ containing B9-Fab $(\sim 8.5 \mu \mathrm{g} / \mathrm{ml})$ diluted $1 / 3(\mathrm{v} / \mathrm{v})$ with RPMI 1640 medium (Sigma Chemical Co., St. Louis, MO, U.S.A.) and incubated at $37^{\circ} \mathrm{C}$ for $30 \mathrm{~min}$. Embryos in control groups were incubated in droplets only with PBS. Embryos were washed three times with PBS and then placed in $30 \mu l$ droplets containing FITC-conjugated goat anti-mouse $\kappa$ chain (Southern Biotech, Birmingham, AL, U.S.A.) diluted 

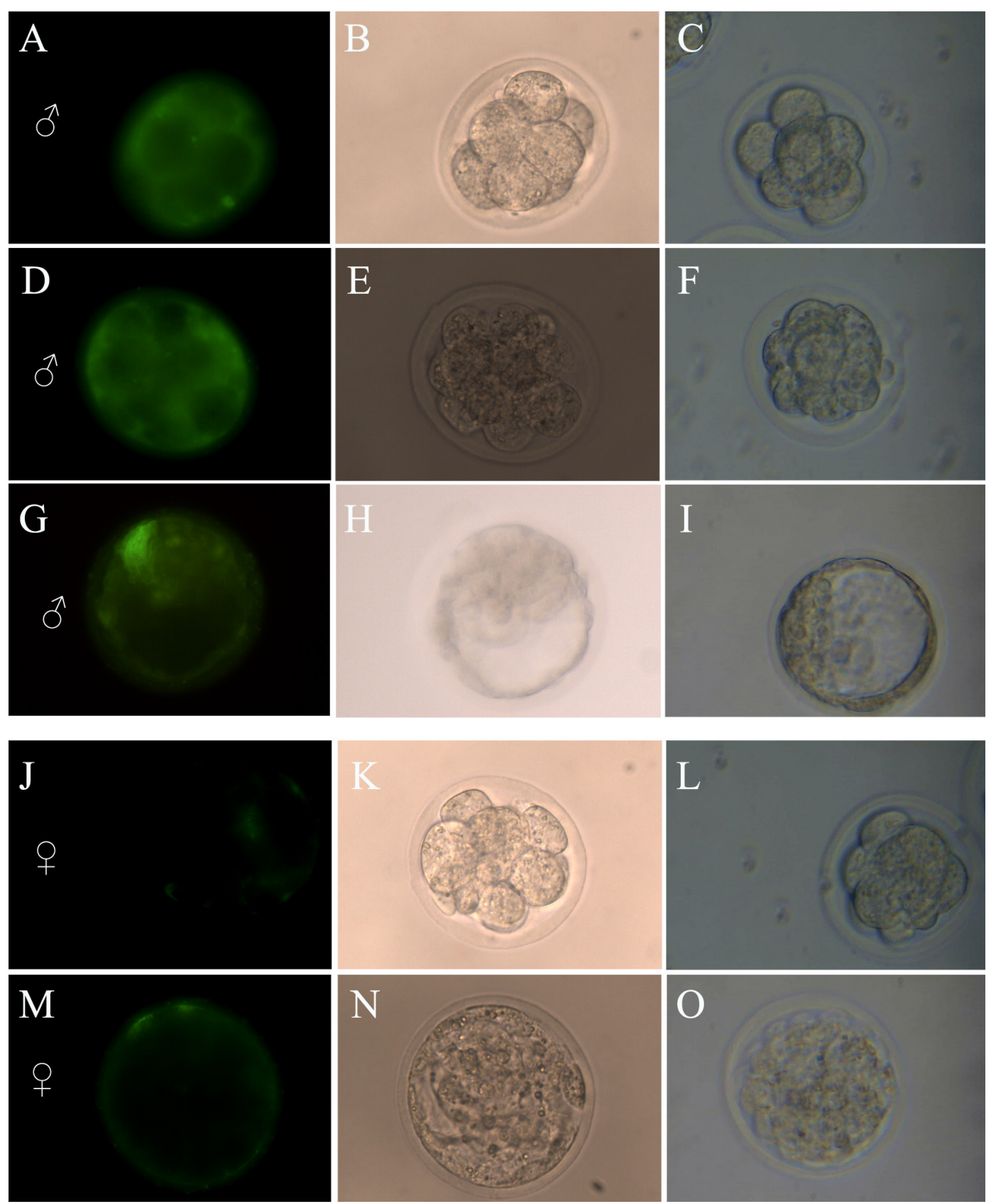

Fig. 1. Immunofluorescent detection of SDM antigen on murine embryos by B9-Fab. Fluorescence and optical images of 8-cell embryos (A and B), morulae (D and E) and expanded blastocysts ( $\mathrm{G}$ and $\mathrm{H}$ ) after being detected with an indirect immunofluorescence assay induced by B9-Fab (classified as males). Also, note the optical image of an 8-cell embryo (C), morula (F) and expanded blastocyst (I) before treatment with B9-Fab. Fluorescence and optical images of morulae $(\mathrm{J}$ and $\mathrm{K})$, and early blastocysts $(\mathrm{M}$ and $\mathrm{N})$ after being detected in an indirect immunofluorescence assay induced by B9-Fab (classified as females). Optical images of a morula (L) and an early blastocyst $(\mathrm{O})$ before treatment with B9-Fab.

1/9 (v/v) with RPMI 1640 medium for signal detection. As a control for the background, only secondary antibodies were added, followed by three additional washes with PBS, and detection of fluorescence. When several cells of either the trophectoderm (TE) and/or the inner cell mass (ICM) dis- played bright fluorescence, the embryo was deemed SDM positive (male), whereas if no cell-specific fluorescence was seen, the embryos were deemed SDM negative (female). A Chi-square test was used to determine any difference from an expected 1:1 sex ratio. 
Table 1. Detection of SDM antigen on murine morulae and blastocysts with B9-Fab

\begin{tabular}{|c|c|c|c|c|}
\hline \multirow{2}{*}{ Presumptive sex } & \multirow{2}{*}{\multicolumn{2}{|c|}{$\begin{array}{l}\text { No. }(\%) \text { embryos } \\
\text { at various stages }\end{array}$}} & \multicolumn{2}{|c|}{ No. $(\%)$ embryos sexed by PCR } \\
\hline & & & Male & Female \\
\hline \multirow[t]{3}{*}{ Male (SDM positive) } & Morula & $330^{\lambda}$ & $28(84.8)$ & $5(15.2)$ \\
\hline & Blastocyst & $27 \hat{O}$ & $23(85.2)$ & $4(14.8)$ \\
\hline & Total & $60(43.5)^{\mathrm{a})}$ & $51(85.0)$ & $9(15.0)$ \\
\hline \multirow[t]{3}{*}{ Female (SDM negative) } & Morula & 41 운 & $5(12.2)$ & $36(87.8)$ \\
\hline & Blastocyst & $37 ㅇ ㅜ$ & $4(10.8)$ & $33(89.2)$ \\
\hline & Total & $78(56.5)^{\mathrm{a})}$ & $9(11.5)$ & $69(88.5)$ \\
\hline Total & & 138 & 60 & 78 \\
\hline
\end{tabular}

a) Proportions of fluorescent and non-fluorescent embryos were not different from a 1:1 ratio $(P>0.05)$; genetic sex was confirmed by PCR.

After fluorescence evaluation, the sex of each embryo was confirmed by multiplex PCR amplification of a murine male-specific sequence (Sry) and concurrent amplification of a non sex-specific Il3 gene (as a positive control). Each embryo was placed in $2 \mu l$ of lysis buffer $(20 \mathrm{mM}$ Tris- $\mathrm{HCl}$, $\mathrm{pH} 8 ; 0.9 \%$ Tween-20;0.9\% Nonidet P- $40 ; 0.4 \mathrm{mg} / \mathrm{ml}$ proteinase $\mathrm{K}$ ) and heated (three cycles of $95^{\circ} \mathrm{C}$ for $8 \mathrm{~min}$ and $60^{\circ} \mathrm{C}$ for $2 \mathrm{~min}$ ). Embryonic DNA in PCR tubes was used as a template; sequences corresponding to the Sry gene and IL3 gene were amplified in two-round PCR reactions (under the same conditions), using two sets of nested outer primer (First round PCR) and inner primer pairs (Second round PCR) as described by Zwingman et al. [15] and Lambert et al. [7], respectively. An initial step at $94^{\circ} \mathrm{C}$ for $5 \mathrm{~min}, 30$ cycles of denaturation at $94^{\circ} \mathrm{C}$ for $30 \mathrm{sec}$, annealing at $58^{\circ} \mathrm{C}$ for $30 \mathrm{sec}$ and synthesis at $72^{\circ} \mathrm{C}$ for $30 \mathrm{sec}$. In addition, an extension time (10 min) was added after amplifications. Purified male and female murine liver DNAs (positive and negative controls, respectively) and distilled water (blank control) were included.

The membrane and inner cell mass of morulae and blastocysts (presumptive males) had bright green fluorescence (Fig. 1); these embryos had unequal distribution of fluorescence, with strong fluorescence over large areas, consistent with high SDM antigen density. In contrast, for presumptive female embryos, embryonic cells had either no fluorescence or a relatively weak green fluorescence, and the zona pellucida had a fluorescent ring (weak green).

A total of 138 morula- and blastocyst-stage embryos were evaluated to detect expression of SDM antigen. Overall, $43.5 \%(60 / 138)$ were classified as fluorescent (presumptive males) and 56.5\% (78/138) as non-fluorescent (presumptive females; Table 1). Furthermore, based on PCR analysis, 51 $(85.0 \%)$ of presumed male embryos were males, whereas $69(88.5 \%)$ of presumed female embryos were females (Table 1).

The overlap image of morula and unfertilized eggs was detected in an indirect immunofluorescence assay induced by B9-Fab; morulae classified as fluorescent were considered male (confirmed by PCR analysis), whereas unfertilized eggs were non-fluorescent.

Non-invasive immunological approaches for sexing embryos, based on either detection of SDM antigen on the cell surface of a male embryo or on temporary developmental arrest of male embryos induced by SDM sera, have considerable appeal $[5,8]$. Anti-SDM antibodies are usually obtained from female laboratory animals (e.g. mice and rabbits) that were immunized with syngenic male splenocytes or other male cells [14]. However, the low affinity of most conventional SDM antibodies limit their utility for embryo sexing [14]. The accuracy of determining sex of early embryos by detection of SDM antigens using indirect immunofluorescence assays or induction of developmental arrest of $\mathrm{H}-\mathrm{Y}$ antibody was approximately $80 \%$ [5]. Furthermore, using induction of developmental arrest by high-titer SDM antisera, $80 \%(8 / 10)$ and $82 \%(9 / 11)$ of bovine embryos were classified as males or females, respectively [8]. It was noteworthy that the male: female ratio of in vitro-produced bovine embryos beyond the 8-cell stage did not significantly differ from 1:1 [5] in a cytotoxicity assay using rat monoclonal $\mathrm{H}-\mathrm{Y}$ antibodies (expected to cross-react with $\mathrm{H}-\mathrm{Y}$ antigens).

Genes encoding variable domains of phage antibody fragments could be engineered in vitro, utilizing the same mechanisms as those of endogenously produced antibodies, although not constrained by tolerance mechanisms in vivo or by the molecular nature of the antigen, all of which should improve binding affinity. In the present study, the affinity and specificity of the B9-Fabs for SDM antigens were engineered by chain shuffling and a guided selection technique, and mouse embryos were subjected to an indirect immunofluorescence assay. Furthermore, in our study, embryos were clearly designated as male or female, due to high-quality fluorescing images. The accuracy of sex determination was consistent with previous investigations [10]. The proportions of fluorescent and non-fluorescent embryos were not significantly different from a 1:1 ratio $(P>0.05)$, consistent with the naturally-occurring ratio of male:female embryos. Moreover, once the B9-Fab was removed from embryos using a non-destructive buffer as described [5], there were no apparent effects on subsequent in vitro development (data not shown). Therefore, B9-Fab antibody fragments have considerable potential for embryo sexing.

The accuracy of sexing murine embryos using B9-Fab was $85.0 \%$ for males and $88.5 \%$ for females, which was comparable to previous reports of accuracy being $84 \%$ for cattle embryos, $85 \%$ for goat embryos and $81 \%$ pigs 
embryos sexed using conventional SDM monoclonal and polyclonal antibodies prepared using male tissue or cells [1, 3]. Furthermore, there were no significant differences in the accuracy of sexing morulae $(84.8 \%$ for males and $87.8 \%$ for females) versus blastocyst embryos $(85.2 \%$ for males and $89.2 \%$ for females) with B9-Fab, which suggested that the immunological assay of SDM antigen was not affected by the stage of embryo development.

It was noteworthy that $\mathrm{B} 9-\mathrm{Fab}$ had roughly a $15 \%$ rate of misdiagnosis for both male and female embryos. Because embryo cells have complex surface components, with various membrane proteins being exposed, we concluded that minor interactions (fluorescence-positive) between nonSDM surface antigens of embryo cells or common components on the cell surface of both sexes, and B9-Fab were observable, which presumably contributed to misdiagnosis in sexing embryos. Lower-quality murine embryos with fluorescence unrelated to presence of SDM antigen might also cause misdiagnosis. However, unlike conventional antibodies against the SDM antigen, SDM B9 Fab fragments could be engineered genetically to enhance specificity and/ or binding activity. In that regard, the amino acid sequence in the high and light chains of B9 Fab could been modified (mutagenesis strategy or combining a bright fluorescent protein with B9 Fab) to improve accuracy. Therefore, although the assay was reasonably accurate, targeted modifications and the effects of those molecular changes on the accuracy of this approach for sexing embryos should be explored in future studies.

In conclusion, the present study confirmed previous reports of the efficiency of sexing early embryos using an antibody against SDM antigen. Notwithstanding, this was apparently the first report of sexing of murine embryos by an indirect immunofluorescence assay induced by novel phage antibody, highlighting potential application of SDM antibodies in assisted reproduction technology.

ACKNOWLEDGMENTS. This work was supported by the National Natural Science Foundation for Young Scientists of China (grant 30901090), the Planned Science and Technology Project of Hunan Province, China (grant numbers 2014FJ2011) and the Scientific Research Fund of Hunan Provincial Education Department (grant 09B046). The $\mathrm{pComb3}$ vector was a gift from the Scripps Research Institute, La Jolla, CA, U.S.A.

\section{REFERENCES}

1. Anderson, G. 1987. Identification of embryonic sex by detection of HY antigen. Theriogenology 27: 81-97. [CrossRef]

2. Hogan, B. F. C. and Lacy, E. 1986. Manipulating the mouse embryo: a laboratory manual, 4th ed., Cold Spring Harbor Laboratory Press, New York.

3. Bredbacka, P. 1998. Recent developments in embryo sexing and its field application. Reprod. Nutr. Dev. 38: 605-613. [Medline] [CrossRef]

4. Chen, C. M., Hu, C. L., Wang, C. H., Hung, C. M., Wu, H. K., Choo, K. B. and Cheng, W. T. 1999. Gender determination in single bovine blastomeres by polymerase chain reaction amplification of sex-specific polymorphic fragments in the amelogenin gene. Mol. Reprod. Dev. 54: 209-214. [Medline] [CrossRef]

5. Gardón, J. C., Agüera, S. and Castejón, F. 2004. Sexing in vitro produced bovine embryos, at different stages of development, using rat $\mathrm{H}-\mathrm{Y}$ antiserum. Theriogenology 62: 35-43. [Medline] [CrossRef]

6. Hossepian de Lima, V., Moreira-Filho, C., De Bem, A. and Jorge, W. 1993. Sex determination of murine and bovine embryos using cytotoxicity and immunofluorescence assays. Theriogenology 39: 1343-1352. [CrossRef]

7. Lambert, J. F., Benoit, B. O., Colvin, G. A., Carlson, J., Delville, Y. and Quesenberry, P. J. 2000. Quick sex determination of mouse fetuses. J. Neurosci. Methods 95: 127-132. [Medline] [CrossRef]

8. Ramalho, M. F., Garcia, J. M., Esper, C. R., Vantini, R., Alves, B. C., Almeida Junior, I. L., Hossepian de Lima, V. F. and MoreiraFilho, C. A. 2004. Sexing of murine and bovine embryos by developmental arrest induced by high-titer H-Y antisera. Theriogenology 62: 1569-1576. [Medline] [CrossRef]

9. Shea, B. F. 1999. Determining the sex of bovine embryos using polymerase chain reaction results: a six-year retrospective study. Theriogenology 51: 841-854. [Medline] [CrossRef]

10. Sutou, S., Kondo, M., Matsuda, M., Kawakura, K., Ohinata, Y., Mitsui, Y. and Matsukuma, S. 2001. HY antigens as Y chromosome-encoded gene products and serologically detectable male antigens (SDM) as testis-or spermatogenesis-linked autosomal gene products. Archiv. Fur. Tierzucht. 44: 677-686.

11. Wachtel, S., Nakamura, D., Wachtel, G., Felton, W., Kent, M. and Jaswaney, V. 1988. Sex selection with monoclonal H-Y antibody. Fertil. Steril. 50: 355-360. [Medline]

12. Wang, N., Xu, D., Yuan, A., Deng, Z., Xue, L. and Cui, S. 2008. Construction and characterization of phage display library: recognition of mouse serologically detected male (SDM) antigen. Anim. Reprod. Sci. 104: 93-110. [Medline] [CrossRef]

13. Wang, N., Yuan, A., Deng, Z., Yang, Q., Ma, J., Tan, Q., Zhang, S., Xue, L. and Cui, S. 2013. Engineering the male-specificity of Fab against SDM antigen by chain shuffling. Theriogenology 79: 1162-1170. [Medline] [CrossRef]

14. Wolf, U. 1998. The serologically detected H-Y antigen revisited. Cytogenet. Cell Genet. 80: 232-235. [Medline] [CrossRef]

15. Zwingman, T., Erickson, R. P., Boyer, T. and Ao, A. 1993. Transcription of the sex-determining region genes Sry and Zfy in the mouse preimplantation embryo. Proc. Natl. Acad. Sci. U.S.A. 90: 814-817. [Medline] [CrossRef] 